Article

\title{
Going Nordic in European Administrative Networks?
}

\author{
Reini Schrama ${ }^{1, *}$, Dorte Sindbjerg Martinsen ${ }^{1}$ and Ellen Mastenbroek ${ }^{2}$ \\ ${ }^{1}$ Department of Political Science, University of Copenhagen, 1353 Copenhagen K, Denmark; \\ E-Mails: reini.schrama@ifs.ku.dk (R.S.), dm@ifs.ku.dk (D.S.M.) \\ 2 Department of Public Administration, Radboud University, 6525 Nijmegen, The Netherlands; \\ E-Mail: e.mastenbroek@fm.ru.nl \\ * Corresponding author
}

Submitted: 15 May 2020 | Accepted: 22 September 2020 | Published: 3 November 2020

\begin{abstract}
The integration and policymaking of the European Union (EU) are claimed to challenge Nordic cooperation as a separate 'common order.' Increasing interdependencies in the EU have forced all EU member states to collaborate and share sovereignty in an increasing number of policy areas. This article studies the coexistence of Nordic cooperation and European integration by taking a network approach. It analyses the extent to which Nordic members of European Administrative Networks 'go Nordic' to solve problems or exchange advice, information and best practices. Based on unique survey data on interactions related to the implementation of EU policies in Social Policy, Health and the Internal Market by national governmental organisations across the EU and the European Economic Area (EEA), we use social network analysis to test for distinguishable patterns of Nordic cooperation. We find evidence to suggest that Nordic cooperation in the EU and EEA is best characterised by differentiated integration. The Nordic states tend to form a separate community for problem-solving and exchanging best practices, advice and information in Health and Social policy networks, but less so in SOLVIT, a network related to the Internal Market.
\end{abstract}

\section{Keywords}

European administrative networks; European integration; EU internal market; EU health policy; EU social policy; Nordic cooperation; policy networks; social network analysis; SOLVIT

Issue

This article is part of the issue "Rediscovering Nordic Cooperation" edited by Anne Elizabeth Stie (University of Agder, Norway) and Jarle Trondal (University of Agder, Norway/ARENA University of Oslo, Norway).

(C) 2020 by the authors; licensee Cogitatio (Lisbon, Portugal). This article is licensed under a Creative Commons Attribution 4.0 International License (CC BY).

\section{Introduction}

Existing literature presents European integration as a major challenge to Nordic cooperation: As European integration has progressed, the Nordic political order has arguably lost some of its relevance (Olesen \& Strang, 2016; Strang, 2016; Sverdrup, 1998). However, political orders could potentially coexist: Being part of a larger political order does not necessarily dissolve pre-existing political networks. The Nordic states could maintain a Nordic nucleus within the larger European setting. In this article, we examine whether and how Nordic cooperation coexists with European integration by taking a network perspective.
Three different expectations on Nordic cooperation concerning European integration can be derived from existing literature. Firstly, Nordic cooperation has been characterised as particularly informal and widespread across the national administrations (Sundelius, 1977; Sundelius \& Wiklund, 1979, 2000), leaving it rather unaffected by further European integration. Secondly, increased cooperation on a European level may make broad cooperation easier and more attractive than interactions amongst the Nordics only (Strang, 2016). As a result, European cooperation may inhibit Nordic cooperation by weakening the political will and opportunity to act regionally (Sverdrup, 1998). Thirdly, in line with theories on differentiated integration (Leruth, 
Gänzle, \& Trondal, 2019; Schimmelfennig, Leuffen, \& Rittberger, 2015), the strength of Nordic cooperation may differ across policy areas because of the varying degrees of institutionalisation through which integration has processed.

Nordic cooperation has long roots. Key institutional developments took place before or alongside European economic integration. A first, Nordic SocialPolitical meeting was held in Copenhagen in 1919, with the aim to coordinate the Nordic approaches to the first International Labour Organization conference to be held the same year (Kettunen, Lundberg, Österberg, \& Petersen, 2016). The Nordic countries were first movers in establishing free movement across borders. Already back in 1943, Sweden had abolished work permit requirement for citizens from Denmark, Finland, Iceland and Norway and, between 1952 and 1957, requirements for visas and passports were gradually abolished between the Nordic countries (Tervonen, 2016). The Nordic Council, established in 1952, became a driving force behind further institutionalisation (Olesen \& Strang, 2016, p. 29). In 1954, a common labour market was agreed upon. The adoption of the Nordic Social Security Convention in 1955 paved the way for equal treatment of Nordic Citizens in terms of welfare rights across the region. In 1957, furthermore, the treaty establishing a Nordic passport union was signed.

These far-reaching agreements paved the way for regular interaction among Nordic politicians and governmental organisations (Kettunen et al., 2016; Strang, 2016). This has led to well-established cooperation between state representatives at both the official and semi-official level (Kettunen et al., 2016, p. 86). At the same time, Nordic economic cooperation as a separate economic order never really institutionalised. In the 1950s, a plan for a Nordic customs union was negotiated, running parallel to the drafting of the European Economic Community. The plan was, however, buried in the light of European developments. Later, at the end of the 1960s, a plan for a Nordic Economic Community (NORDEK) was drafted, but never signed (Strang, 2016, p. 5).

Overall, Nordic cooperation has been challenged by parallel European integration. In 1973, Denmark became a member of the European Community, followed by Sweden and Finland in 1995. Norway and Iceland remain outside, but are members of the European Economic Area (EEA) and thus members of the internal market, the rules of which they have to apply. As European integration progressed and took over as a dominant theme in Nordic Council meetings (Olesen \& Strang, 2016, p. 33), it increasingly overshadowed Nordic cooperation (Kettunen et al., 2016; Olesen \& Strang, 2016; Tervonen, 2016).

In this article, we examine Nordic cooperation in three European Administrative Networks (EANs). The networks relate to policy areas that display a variant degree of EU involvement, from "limited EU poli- cy involvement," i.e., health and welfare, to "considerable EU involvement," i.e., internal market (Buonanno \& Nugent, 2013, pp. 7, 11). The first network is the Administrative Commission for the Coordination of Social Security Systems (AC). Being established in 1958, the network is one of the oldest EANs. The network assists the Commission on Regulation 883/2004 concerning welfare across borders, i.e., the rights of European citizens to social security when they reside or work in another member state. The task of the Administrative Commission is to facilitate the uniform application of Community Law. To do so, it may issue recommendations and make decisions on how the articles of the relevant EU regulation shall be interpreted and applied. It is thus a forum for both information exchange and problem-solving.

The second network is the cross-border healthcare (CBHC) expert group, established as part of the Patients' Rights Directive 2011/24 (PRD). The role of this network is to assist the Commission on the implementation of the PRD, laying down the rules and conditions when European citizens seek planned healthcare treatment in another member state. The network foremost exchanges information between participants and has no direct problem-solving function.

The third network is SOLVIT. This network was set up in 2001 to address misapplication of internal market law. SOLVIT is a problem-solving network and has considerable competences in terms of case handling. The network consists of national SOLVIT centres. Citizens or businesses can submit cases concerning the misapplication of internal market law to the SOLVIT centre in the country where one resides or the business is established. This SOLVIT centre then is to contact the SOLVIT centre in the member state where the alleged misapplication has taken place. Consecutively, the two SOLVIT centres have to examine the case, aiming to solve misapplication if this is uncovered.

In all three networks, network members may interact in a plenum, in subgroups, or bilaterally-between those involved in a specific case or an issue addressed. These interactions can have different aims. To begin with, they may aim at solving problems related to the interpretation or application of EU rules. Furthermore, interactions may aim at the exchange of information, of advice on the interpretation or application of EU rules, or of best practices for doing so.

We collected data on all four types of interaction: problem-solving, exchange of information, exchange of advice and exchange of best practices. We did so by using a self-developed survey to map out the structure of each network. By adopting a social network approach, we put the bilateral interactions of transnational bureaucracy (Strang, 2016; Sundelius, 1977; Sundelius \& Wiklund, $1979,2000)$ at the centre of our analysis, allowing us to assess whether there is indeed a tendency to 'go Nordic' in EANs. We study the strength of Nordic cooperation in each network by visualising network interactions to 
detect the existence of a separate Nordic community and to test whether interactions cluster among Nordic network members.

We find that, despite long-lived European integration, there is still a strong Nordic community within the broader European political order. Nordic cooperation and European integration coexist, without the latter crowding out the former. However, our findings also show that the strength of Nordic cooperation is differentiated (Leruth et al., 2019; Schimmelfennig et al., 2015): It depends on the level of institutionalisation, which varies across policy areas.

In the following sections, we first set out our theoretical argument and expectations on the strength of Nordic cooperation in EANs. After discussing transgovernmental cooperation in EANs more generally and framing Nordic cooperation as informal transgovernmentalism, we develop three different expectations on Nordic cooperation in light of European integration. The subsequent section details our methodology, data collection and operationalisation. Next, we discuss the results from our study in terms of both the visualisation of detected communities within the networks and the significance of Nordic cooperation. Finally, we discuss the implications of our findings in the conclusion.

\section{Theory}

\subsection{Nordic Cooperation in European Administrative Networks}

This article analyses Nordic cooperation against the background of ever-increasing European integration. Since its inception, European integration has extended in scope and substance, with the European Commission as the core executive. However, in light of its extensive legislative and administrative tasks, the Commission's resources and formal competences are limited, especially in the realm of policy implementation and enforcement. It therefore depends strongly on cooperation with national administrations to realise its functions and objectives (Mastenbroek \& Martinsen, 2018; Trondal \& Peters, 2013). This form of regular and multilevel cooperation occurs in what has been termed as the European Administrative Space (EAS; Hofmann, 2008; Olsen, 2003) or an emergent European Executive Order (Trondal, 2010). The EAS has institutionalised a common administrative capacity, driven by the interactions between the Commission and national administrative organisations. The EAS has been defined as a space "in which increasingly integrated administrations jointly exercise powers delegated to the EU in a system of shared sovereignty," marked by "a high degree of close administrative cooperation between all levels of member states' administrations with the European institutions and bodies in various policy phases" (Hofmann, 2008, p. 662). Seconded National Experts, European agencies and EU committees are important parts of the EAS in EU agenda-setting and decision-making processes (Egeberg \& Trondal, 2009; Trondal, 2010; Trondal \& Peters, 2013). Also, EANs play an important role in the implementation and enforcement of EU policies (Mastenbroek \& Martinsen, 2018).

EANs are key components of the EAS. They can be defined as "networks that consist of institutional representatives of national executives-primarily departments and/or agencies-with tasks in the realm of national implementation or enforcement of EU policies" (Mastenbroek \& Martinsen, 2018, p. 423). While displaying differences in organisation and structure, EANs share two key features: Their members are civil servants and they are tasked with improving the national implementation and enforcement of EU policies. In both respects, EANs are similar to transgovernmental networks, which the International Relations literature has presented (Bach \& Newman, 2010; Eberlein \& Newman, 2008; Slaughter, 2004). EANs are mostly transgovernmental in the sense that they are constituted by national and EU governmental actors, represented by civil servants meeting with their peers from other member states.

In terms of tasks, EANs deal with a fundamental dilemma of supranational governance. On the one hand, states are increasingly interdependent and commit themselves to cross-border cooperation, which translates in international norms, rules and policies. On the other hand, they are reluctant to delegate the competencies required for the implementation of these international agreements, which thus remain at the national level. To escape this supranational governance dilemma, EANs are to assist the Commission in overseeing the implementation and enforcement of EU rules. Network interactions are supposed to attenuate national interests and instead establish an enabling environment for the implementation and enforcement of mutual agreements (Eberlein \& Newman, 2008).

The more specific functions of EANs and the relational structure between actors are likely to differ across networks. In terms of functions, it matters what flows in the network, i.e., what characterises interactions. Some networks are primarily information-based. These are labelled information networks (Slaughter, 2004 , p. 56). Here, actors exchange information about implementation and enforcement practices and challenges. Additionally, participants may exchange best practices, or seek advice from other peers on how to deal with implementation/enforcement problems. Other networks have problem-solving competences. They may solve cases on misapplied EU law or issue administrative decisions on how to interpret or implement specific articles in a legal act. Both information networks and problem-solving networks are regarded as key to learning. Regular network cooperation teaches actors about new or different approaches to implementation-related problems and facilitate expert-driven policy learning (Vantaggiato, 2019). By exchanging their ways of doing things, actors learn from one another. 
The relational structure of networks, as constituted by network interactions, also varies. This structure may be largely horizontal, with network members interacting amongst each other on equal terms and to the same extent (Slaughter, 2004; Slaughter \& Hale, 2010). Alternatively, networks may develop a more asymmetric or vertical structure, the Commission or a member state representative constituting a nodal position, sometimes to the extent of becoming the "teacher of norms" (Versluis \& Tarr, 2013). The structure of a network is important because the central actors in a network are more likely to control interactions. This allows them to put a substantive mark on interactions, deciding what constitutes relevant information or what is a best practice, as well as allowing them to provide advice to other actors. They thus become more in charge of defining problems and solutions, which is by no means neutral but instead a rather powerful position from which to influence European integration. Controlling and distributing information matters.

The internal structure of a network thus informs us about the power distribution in a network. The relational structure offers an opportunity structure to members, which they can use to set agendas and control how resources, such as information, best practices and advice, are shared between actors (Vantaggiato, Kassim, \& Wright, 2020). Yet, the relational structure of a network can also be clustered. Some clusters may be rather insulated from the rest of the network, being incapable or unwilling to reach out. Likeminded states may seek one another and, instead of learning across differences (Sabel \& Zeitlin, 2008), they will primarily turn to their counterparts with whom they already share experiences to solve problems and exchange information, best practices and advice.

\subsection{Nordic Cooperation as Informal Transgovernmentalism}

The case of Nordic cooperation fits well with the concept of transgovernmental relations, which refers to interactions among administrative units of national governments (Keohane \& Nye, 1974). As emphasised by Sundelius (1977) and Sundelius and Wiklund (2000), Nordic relations are rather treated as an extension of domestic policymaking than handled through a single foreign policy channel. They found that interactions are mainly informal, i.e., without formal decision-making authority, and take place predominantly among national civil servants handling day-to-day activities. In doing so, civil servants in governmental sub-units maintain considerable independence vis-à-vis their political principals. Crucially, Nordic cooperation takes place through such transgovernmental interactions between the respective administrations. These interactions are broad in scope and run deep inside the national bureaucracies (Sundelius \& Wiklund, 1979, 2000). Informal interactions and cooperative behaviour among Nordic officials are stimulated through socialisation processes, enabled by regular meetings and social activities enhancing social and personal relations among them (Sundelius, 1977).

Moreover, more informal cooperation inspired the institutionalisation of the Nordic community in the first place. Instead of constituting a basis for transgovernmental interactions amongst Nordic states, these institutionalised structures were established to codify existing practices and to facilitate greater coordination (Sundelius \& Wiklund, 1979, 2000). In turn, the institutionalisation of regular meetings enhanced interactions and continuous contacts (Sundelius \& Wiklund, 1979, 2000). The importance of these informal bilateral interactions among the Nordics has been emphasised by Ojanen (1999). In her view, informal cooperation in the Nordic community takes place to a greater extent than formal cooperation; informal links being the norm and ideal for Nordic cooperation. She posits that these bilateral relations are a result of existing parallel national structures in Nordic administrations, which make it easy to identify the right counterpart. These bilateral relations also function as a driver for bringing Nordic administrations closer together (Ojanen, 1999).

While Nordic cooperation is mostly studied as multilateral coordination, there has been a plea for a more systematic analysis of the bilateral relations within the Nordic community (Strang, 2016). The appeal to map interaction patterns has been echoed in studies on EANs more generally (Mastenbroek \& Martinsen, 2018; Vantaggiato, 2019). It is not only important to see how frequently national administrations interact and about what (Sundelius, 1977), but also crucial to see who interacts with whom and for which purpose (Martinsen, Schrama, \& Mastenbroek, 2020). Along these lines, Nordic cooperation can take the character of a set of bilateral interactions between national administrations.

\subsection{Nordic Cooperation in Light of European Integration}

We develop three expectations on Nordic cooperation in light of European integration. First, the informal character of transgovernmental relations among the Nordics could be an asset for Nordic cooperation, despite more European integration. While European integration is based on more formal commitments to a supranational union, not allowing formal groupings of countries, Nordic cooperation is characterised mostly by the joint management of relations among Nordic administrations on the subnational level (Ojanen, 1999). In that sense, the EU does not inhibit the interactions among the Nordics, and European integration should not pose a threat to Nordic cooperation. Even more so, it is common for like-minded countries to cooperate more within the EU, particularly within EANs (Martinsen et al., 2020; Vantaggiato, 2019). We expect that the long history of informal cooperation has deepened Nordic transgovernmental relations (Ojanen, 1999; Sundelius \& Wiklund, 1979). We thus assume Nordic cooperation to be particularly 'strong,' 
meaning that it is more straightforward for civil servants to interact with their Nordic counterparts instead of their European ones:

Expectation 1: Nordic cooperation is strong across policy areas.

Instead, we may expect Nordic cooperation to be stronger in some policy areas than others. In line with theories on differentiated integration (Leruth et al., 2019; Schimmelfennig et al., 2015), the level of integration can be assumed to differ across policy areas. In particular, we expect that the extent of institutionalisation in a particular area affects the strength of Nordic cooperation. Existing institutionalisation begets interaction. The institutionalisation of Nordic cooperation consists of three major achievements, namely: a passport union, a common labour market and the social security convention (Kettunen et al., 2016). Other types of free movement, however, never materialised on the Nordic level, but rather on the European level in the form of the European internal market. Instead, the Nordics have a long tradition of free movement of people, labour and the development of a distinct, Nordic type of welfare state. Because of this deep institutionalisation on the Nordic level, state representatives at both the official and semi-official level have established continued cooperation (Kettunen et al., 2016). In addition to already established institutional cooperation in certain policies, institutional similarity may tie Nordic representatives tighter together. Rose (1993) argues that, due to similarity in economic resources and closeness in both ideology and geography, the Nordics are particularly well suited for lesson-drawing across borders.

More recently, similar arguments and empirical accounts about the importance of institutional similarity for cooperation have been put forward in the literature on transgovernmental cooperation (Efrat \& Newman, 2016, 2017) and EANs (Martinsen et al., 2020; Van Der Heijden, 2019; Vantaggiato, 2019). The familiarity of institutions and similarity of domestic experiences and common challenges facilitate interaction and the exchange of resources across national administrations. A Nordic model of welfare, including health, is often presented to exist where common social norms and institutions are shared, and which is characterised by relatively generous welfare protection, an encompassing national health service system, tax-financing and universal coverage of the population (Bambra, 2007; Kettunen et al., 2016; Martinsen et al., 2020; Wendt, 2009). Therefore, deeply institutionalised Nordic models in areas of health and welfare policies will make it particularly easy for civil servants from the Nordics to interact with one another. On the other hand, apart from the free movement of persons, other types of free movement did not materialise at the Nordic level but developed first and foremost in the European internal market. Also, Nordic economic cooperation as a separate economic order has not institution- alised. We expect this lack of institutionalised Nordic economic cooperation to affect civil servant interaction in the area of the internal market:

Expectation 2: Nordic cooperation is stronger in areas of health and welfare policy than in the area of internal market policy.

At the same time, Strang (2016, p. 17) rightly asks: "Why would a Dane cooperate with a Finn, instead of a German?" In other words, are the Nordics more integrated amongst themselves than with other EU member states? There are three reasons for a potential crowdingout effect of European integration on Nordic cooperation. First, increased involvement in EANs makes it easier to interact with states beyond the Nordics (Strang, 2016). This renders Nordic cooperation less relevant. Transgovernmental cooperation thus becomes increasingly less uniquely Nordic (Browning, 2007; Lawler, 1997). Second, increased European integration may even inhibit Nordic cooperation, as it weakens the political will and opportunity to act regionally. Further institutionalisation of the European Union is argued to lead to the demise of formal cooperation among the Nordics (Sverdrup, 1998). The constant deepening of European integration has increased the interdependencies of Nordic states with non-Nordic EU members and provided most policy issues with both a Nordic and an EU dimension (Olesen \& Strang, 2016). In sum, deepening European integration has affected the political motivation and the opportunity structures for interaction and exchange among the Nordics. As a result, we may expect that there is no significantly stronger cooperation among the Nordics than among all European network members:

Expectation 3: Cooperation is not stronger among Nordics than across the rest of Europe.

In the next section, we discuss the methods we use to put these expectations to the test.

\section{Methods}

\subsection{Social Network Analysis}

To gain insight into the degree of Nordic cooperation in the context of European integration we use social network analysis. This method allows us to place bilateral interactions among administrative units in the Nordics and all EU member states at the centre of analysis. The pattern of interactions forms a network in which each national administrative unit is positioned concerning its counterparts. The network data enables us to do two separate analyses.

First, we will visualise network interactions and run a community-detection algorithm to ascertain whether the administrative units of the Nordic states can be captured as a separate community of preferred partners 
within the overall network. Communities in networks can be defined as subnetworks in which the interactions within are denser than the interactions outside of it (Murata, 2010). In other words, such clusters of national administrative units are more closely related to each other than they are with other counterparts in the network. To detect such communities we use an algorithm, called walktrap, which randomly 'walks' through the network until it gets 'trapped' into a densely connected subnetwork (Pons \& Latapy, 2005, p. 1). Simply put, the walktrap algorithm runs short random walks across four ties from one network member to another as it calculates the modularity score. This score measures the degree to which each tie falls within a certain community compared to what you would expect if ties were distributed at random. This type of bottom-up cluster analysis seeks to optimise the modularity score to iteratively detect the number of communities present in the network (Murata, 2010). After running the communitydetection algorithm, we visualise the network of interactions and colour each separate community to see whether the Nordics indeed tend to belong to the same community or subnetwork.

Next, we use Exponential Random Graph Models to test whether Nordic cooperation is significantly more likely than cooperation among national administrative units across Europe. These models are appropriate for analysing the inherently relational structure of networks (Handcock, Hunter, Butts, Goodreau, \& Morris, 2008). They enable us to explicitly model the likelihood that the Nordics interact with one another instead of with other national administrative units. Interactions can take on several different forms; counterparts can exchange information, advice or best practices, but they can also engage with one another to solve problems related to their administrative tasks. We model each interaction type separately for all different EANs in our study.

\subsection{Data Collection and Operationalisation}

We collected the data on each interaction type for the EANs across the policy domains using our own online survey tool. We distributed the surveys to one representative from each member of the network separately for SOLVIT, the Administrative Commission and the CBHC expert group.

In each survey, we asked the respondents with which other national representatives they were most frequently in contact to exchange 1) advice, 2) best practices, 3) information and 4) to resolve problems concerning their relevant administrative tasks. We treat all network interactions as non-directed network ties. For example, if a national representative in Sweden indicated an exchange of information with a national representative in Norway, we assume that both were involved in this relationship. Each type of bilateral interaction results in a distinct adjacency matrix for every EAN. We used these matrices to visualise the networks and their communi- ties and included them as the dependent variables in our Exponential Random Graph Models.

We conducted the survey on SOLVIT among all national SOLVIT centres in 2018 , with a response rate of $97 \%$. We did not receive a response from Iceland. We distributed a similar design survey among national representatives of the Administrative Commission in 2018, with a response rate of $100 \%$. In 2019 , we conducted our survey on the national representatives of the CBHC expert group, reaching a response rate of $87 \%$. We did not receive a response from Croatia, Iceland, Spain and the United Kingdom. Such high response rates are sufficient to accurately represent and model the networks as if they were complete (Borgatti, 2006). Unfortunately, we do miss information on the position of Iceland in the network of the $\mathrm{CBHC}$ expert group; they neither participated in the survey nor were named by other members as most frequent contacts. Also, Norway and Iceland are not members of the Administrative Commission, where they only have observer status.

To test whether the Nordics interact significantly more with one another than with any other network member, we created a variable indicating which member is Nordic (coded as 1) and which member is not (coded as 0). We defined Denmark, Finland, Norway, Sweden and Iceland as Nordic states. In the Exponential Random Graph Models, we included Nordic cooperation as a dyadic attribute, indicating all interactions among the Nordics compared to interactions with non-Nordics.

We controlled for inherent interdependencies within the networks by taking into account transitivity. This network trait denotes the commonly found tendency of network members to close triads, meaning that one is more open for interactions with those that one already knows indirectly through others (Goodreau, Kitts, \& Morris, 2009). We operationalise this by including a statistic called geometrically weighted edgewise shared partners (GWESP) in our models. By measuring transitivity in this way, we also account for the fact that there is a declining positive impact for each additional shared partner (Snijders, Pattison, Robins, \& Handcock, 2006).

\section{Results}

\subsection{Network Visualisations and Community Detection}

To gain insight into the patterns of interaction and the component of Nordic cooperation within the context of European policy implementation, we visualise all four types of network interactions for each EAN (Figures 1 to 3 ). The identified communities are coloured differently and divided into separate clusters. This tells us how many communities were identified in each network graph and whether there is a Nordic community amongst them. The squared nodes indicate which of the network members are Nordic states.

First, as to the Administrative Commission, Sweden, Denmark and Finland indeed belong to the same com- 
munity for all four types of interaction (see Figure 1). However, they do not form a secluded community, as this subnetwork comprises non-Nordic countries as well. With regard to information exchange, this community is rather broad and at the core of the network. Concerning the exchange of advice and best practices, the Nordics involve the Baltic states as well as the United Kingdom and Ireland. Problem-solving in the Administrative Commission shows the strongest Nordic cooperation, as they belong to a separate community, only including Latvia. Overall, Nordic cooperation is visible in the network coordinating social security systems, while the Nordics are more integrated into the network more generally.

Turning to the $\mathrm{CBHC}$ expert group, secondly, we see that interactions are particularly clustered among the Nordic states. While we have no data on Iceland, we see that Norway, Sweden, Denmark and Finland tend to exchange information, advice and best practices more than with their other European counterparts (see Figure 2). To a somewhat lesser degree, this is also true for problem-solving. When they do interact with non-Nordic administrative units, these tend to be from the Baltic states. Particularly the relationship between Finland and Estonia is strong. Nordic cooperation thus seems particularly strong when it comes to the exchange or resources among national administrative units coordinating healthcare on a European level.

Third, there is no clear Nordic community within SOLVIT (see Figure 3). Iceland, Norway, Sweden, Denmark and Finland are mostly part of separate communities, interacting more with non-Nordic states than with each other. This finding, which is in line with our third expectation, shows that the Nordics are integrat-
AC - Advice

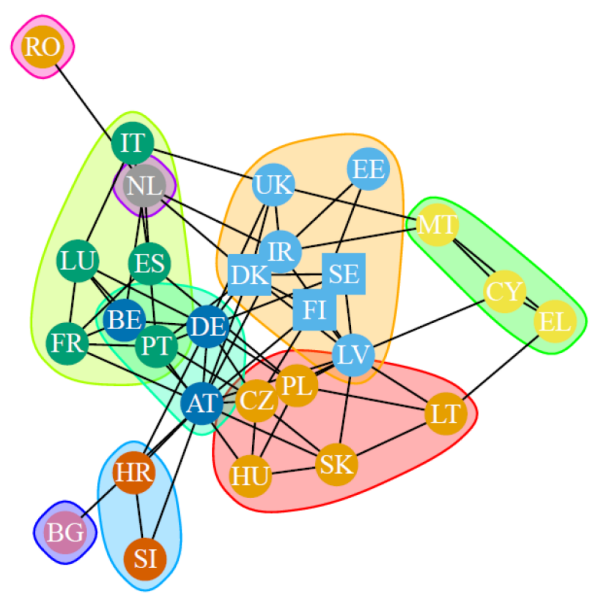

AC - Information

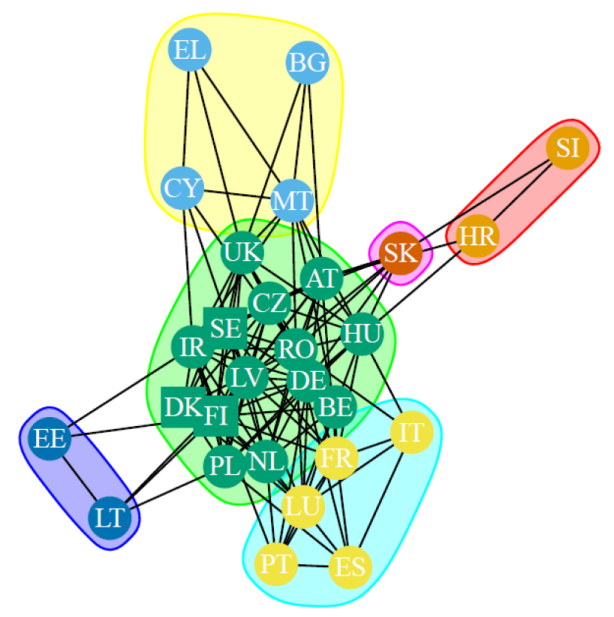

AC - Best practices

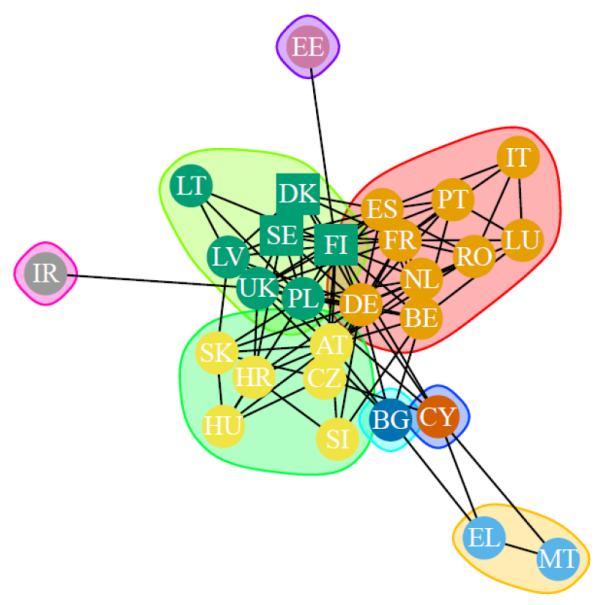

AC - Problem solving

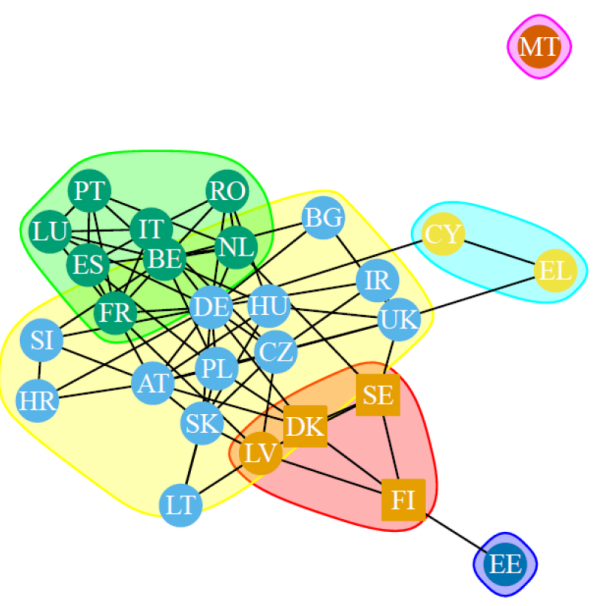

Figure 1. Network visualisation of interactions in the Administrative Commission with community detection. Notes: Each colour represents a different detected community. Nordic states are represented by a square; all others are represented by a circle. 


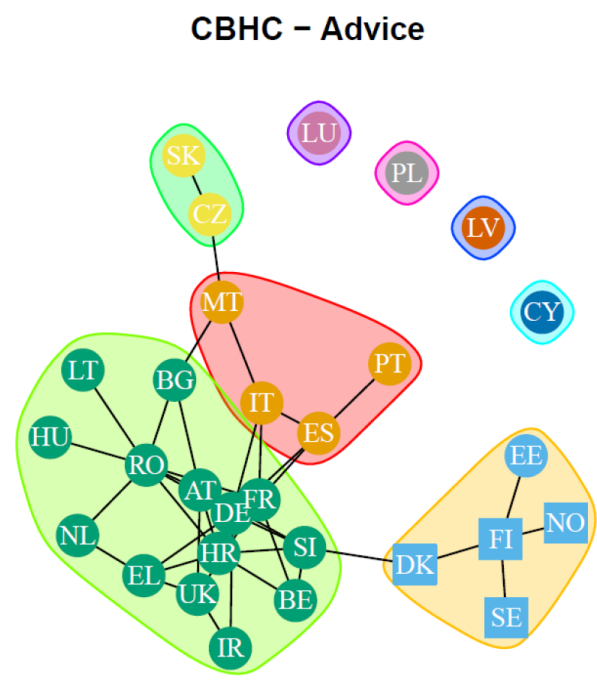

CBHC - Information

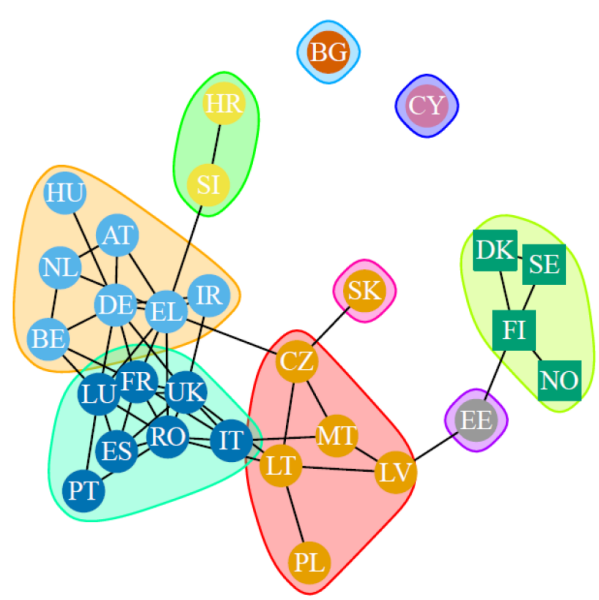

CBHC - Best practices

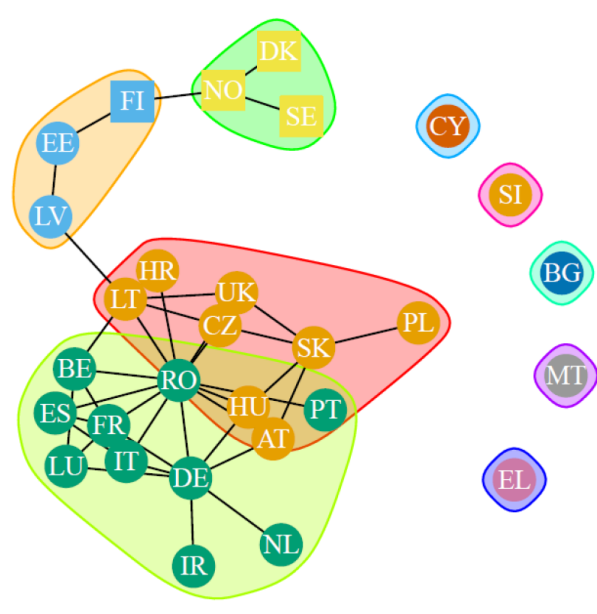

CBHC - Problem solving

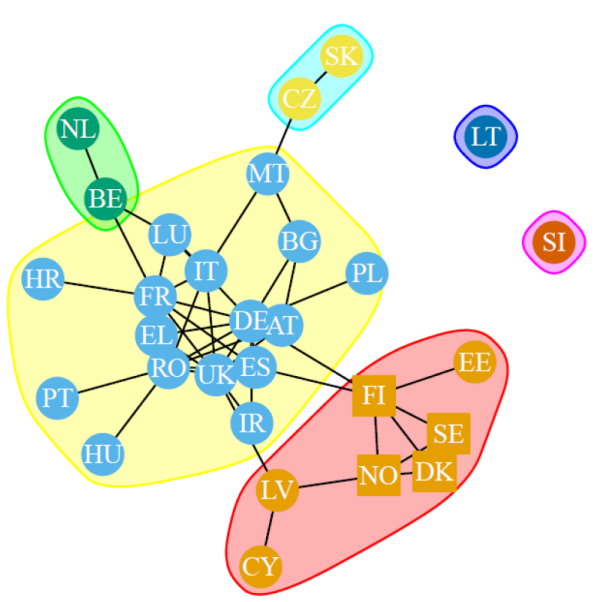

Figure 2. Network visualisation of interactions in the CBHC expert group with community detection. Notes: Each colour represents a different detected community. Nordic states are represented by a square; all others are represented by a circle.

ed within the larger European context to the extent that there is no clear sign of Nordic cooperation in the context of internal market policy.

\subsection{Modelling Nordic Cooperation Within European Administrative Networks}

To test the significance of Nordic cooperation, we developed an Exponential Random Graph Model for every type of interaction in each EAN (see Table 1; Goodness of Fit diagnostics are in the Supplementary File). We control for transitivity, which tends to make interactions among already indirectly related nodes more likely, and see whether Nordic states interact significantly more with one another than with other members. The structural tendency to close triads is significant across networks and interaction types, indicating an overall dense interaction level in EANs.
First, in line with our community detection, we find significant Nordic cooperation within the Administrative Commission when it comes to problem-solving. All else being equal, the Nordics are almost twice more likely to interact to solve problems with one another than they are with other members of the Administrative Commission (odds ratio $=1.90, p<0.1$ ). Odds ratios can be calculated by exponentiating the relevant model coefficient. We do not find similar effects for the exchange of advice, best practices or information. This is likely due to the fact, as indicated by the community detection stage, that Nordic cooperation in this policy area does not preclude interactions with other members.

Furthermore, we find particularly significant and strong Nordic cooperation in the CBHC expert group, for all types of interactions. Administrative units of the Nordic states are more than five times as likely to exchange advice with other Nordics than with non- 
SOLVIT - Advice

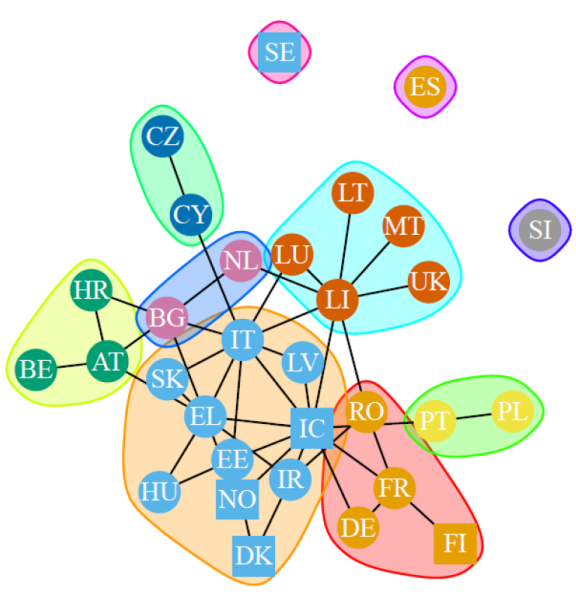

SOLVIT - Information

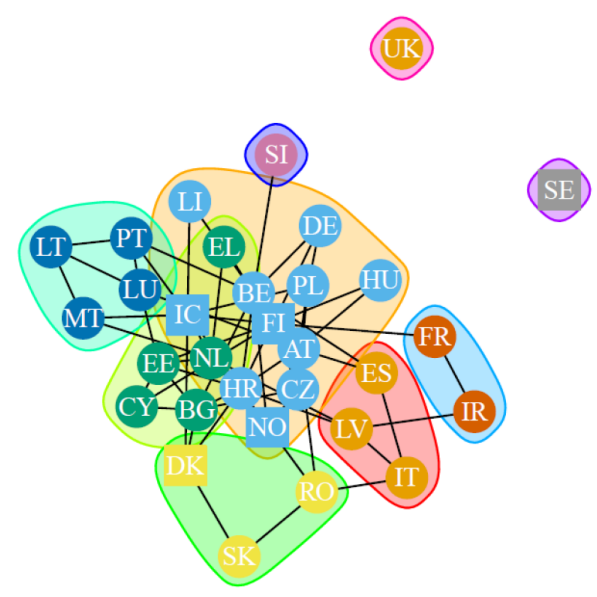

SOLVIT - Best practices

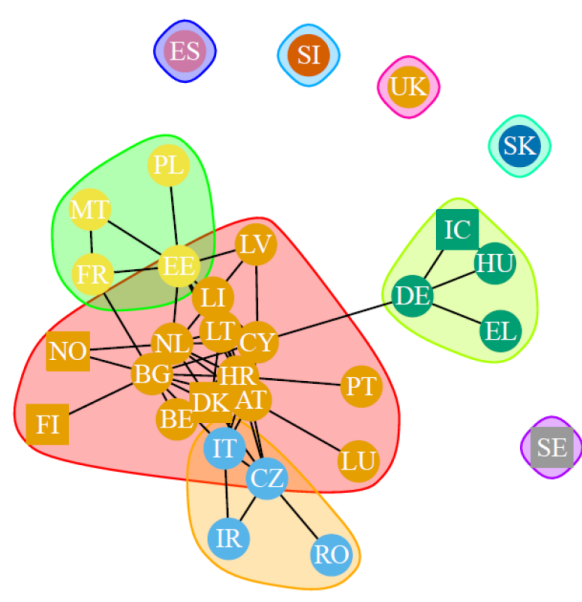

SOLVIT - Problem solving

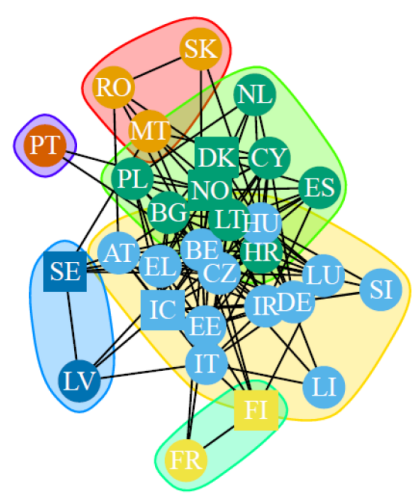

Figure 3. Network visualisation of interactions in SOLVIT with community detection. Notes: Each colour represents a different detected community. Nordic states are represented by a square; all others are represented by a circle.

Nordic counterparts (odds ratio $=5.16, p<0.05$ ). This effect is even stronger for the exchange of best practices, for which Nordic interactions are seven times more likely (odds ratio $=7.25, p<0.01$ ). The effect is strongest for information exchange: Here, interactions with other Nordic members are more than nine times as likely as interactions with non-Nordic members (odds ratio $=9.23, p<0.01)$. At the same time, problemsolving among the Nordics is more than twice as likely compared to the non-Nordic states (odds ratio $=2.35$, $p<0.01)$. This confirms our earlier descriptive finding that, in the area of EU healthcare policies, Nordic cooperation is particularly strong.

Finally, we find no significant effect on Nordic cooperation concerning interactions between SOLVIT centres. In accordance with our community detection, the Nordics are as likely to cooperate with each other as they are with other European SOLVIT centres. Nordic cooperation does not seem to be of any significance in the internal market policy area, which is an area dis- playing extensive European integration and no separate Nordic integration.

In sum, Nordic cooperation is visible in EANs concerning the implementation of both European health and social policy. Interactions have a particularly Nordic character in the area of healthcare. By contrast, we find no Nordic clustering of interactions in the area of internal market policy. This supports our second expectation that Nordic cooperation is differentiated. In other words, Nordic cooperation seems to depend on the level of institutionalisation, which differs across policy areas. The presence of both deeply-rooted Nordic welfare models and existing Nordic cooperation that predates European cooperation in the health and social welfare policy domain, seem to underpin further Nordic cooperation. Vice versa, the Nordic component in European cooperation is insignificant in internal market policy, an area in which Nordic cooperation was weak to begin with, European integration being much more advanced. 
Table 1. Exponential Random Graph Models.

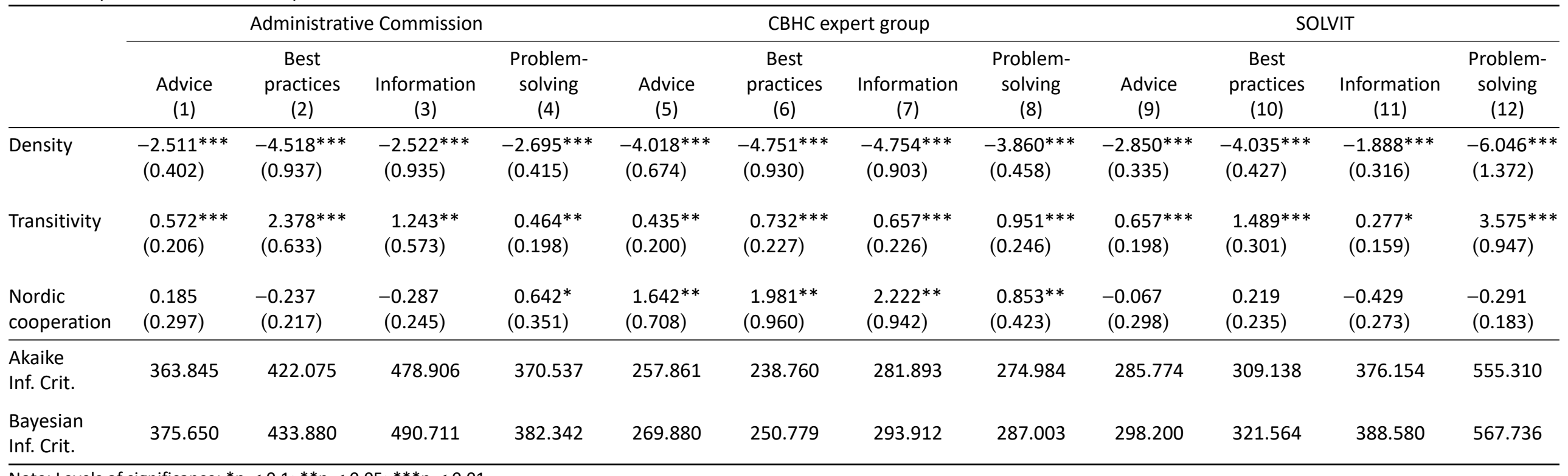

Note: Levels of significance: ${ }^{*} \mathrm{p}<0.1 ;{ }^{* *} \mathrm{p}<0.05 ;{ }^{* * *} \mathrm{p}<0.01$. 


\section{Conclusion}

Across the board, Nordic interactions have proven rather resilient to European integration, contrary to the expectation formulated in existing literature (Olesen \& Strang, 2016; Sverdrup, 1998). Our study has shown that a strong Nordic community still exists within the broader European community when it comes to interactions concerning the implementation and enforcement of EU rules. This demonstrates that political orders can very well overlap and exist simultaneously. Being part of a larger political order does not inhibit Nordic cooperation. In fact, we find that going Nordic is still very much apparent within EANs.

However, the Nordic effect seems contingent on the level of institutionalisation, which differs across policy areas. Our findings support the differentiation hypothesis on regional integration (Leruth et al., 2019; Schimmelfennig et al., 2015). Nordic subnetworks in EANs exist in those policy areas in which Nordic cooperation predates European integration, and was maintained in parallel to later EU developments. Both the established cooperation and the institutional similarity of the Nordic welfare model (Kettunen et al., 2016) appear to ensure the preservation of Nordic cooperation in the health and social welfare policy domain. The finding that institutional similarity is crucial for selecting partners for cooperation and lesson drawing (Rose, 1993) confirms earlier studies on transgovernmental interactions (Efrat \& Newman, 2017; Martinsen et al., 2020; Van Der Heijden, 2019; Vantaggiato, 2019). Instead, in the strongly Europeanised area of internal market policy, where Nordic cooperation was never very successful and a clear Nordic model remained absent, we found no significant Nordic cluster in interactions.

In addition to our finding that the Nordics tend to interact with their Nordic counterparts in areas of previous Nordic cooperation and development of a Nordic model, we find that there is a Baltic connection as well. This indicates that Nordic cooperation may extend its regional base, to the extent of including the Baltics. Even though the Baltic states never really became official players in Nordic cooperation (Olesen \& Strang, 2016), initiatives from the 1990s to establish cooperation frameworks may have led to the development of this Nordic-Baltic connection. The precise background of this finding requires follow-up research.

In sum, the findings suggest a link between previously institutionalised Nordic interactions and the bilateral interactions among officials in administrative units. The exchange of resources such as information, best practices and advice as well as interactions to solve problems related to the implementation of EU policies in the national context is clearly structured along institutional dimensions shaped by Nordic cooperation. This emphasises the importance of studying the actual interactions that make up transnational bureaucracy (Strang, 2016; Sundelius, 1977; Sundelius \& Wiklund, 1979, 2000) and their networked structure (Martinsen et al., 2020; Mastenbroek \& Martinsen, 2018; Vantaggiato, 2019) to assess the relevance of Nordic cooperation within the broader political order.

\section{Acknowledgments}

We thank our anonymous reviewers for their helpful comments. The research for this article was funded by the Danish Council for Independent Research, grant. no. DFF-7015-00024.

\section{Conflict of Interests}

The authors declare no conflict of interests.

\section{Supplementary Material}

Supplementary material for this article is available online in the format provided by the author (unedited).

\section{References}

Bach, D., \& Newman, A. L. (2010). Transgovernmental networks and domestic policy convergence: Evidence from insider trading regulation. International Organization, 64(3), 505-528.

Bambra, C. (2007). Going beyond the three worlds of welfare capitalism: Regime theory and public health research. Journal of Epidemiology \& Community Health, 61(12), 1098-1102.

Borgatti, S. P. (2006). Identifying sets of key players in a social network. Computational and Mathematical Organization Theory, 12(1), 21-34.

Browning, C. S. (2007). Branding Nordicity. Cooperation and Conflict, 42(1), 27-51.

Buonanno, L., \& Nugent, N. (2013). Policies and policy processes of the European Union. London: Palgrave Macmillan.

Eberlein, B., \& Newman, A. L. (2008). Escaping the intergovernmental governance dilemma? Incorporated transgovrnmental networks in the European Union. Governance, 21(1), 25-52.

Efrat, A., \& Newman, A. L. (2016). Deciding to defer: The importance of fairness in resolving transnational jurisdictional conflicts. International Organization, 70(2), 409-441.

Efrat, A., \& Newman, A. L. (2017). Divulging data: Domestic determinants of international information sharing. The Review of International Organizations, 13, 395-419.

Egeberg, M., \& Trondal, J. (2009). National agencies in the European administrative space: Government driven, commission driven or networked? Public Administration, 87(4), 779-790.

Goodreau, S. M., Kitts, J. A., \& Morris, M. (2009). Birds of a feather, or friend of a friend? Using exponential random graph models to investigate adolescent 
social networks. Demography, 46(1), 103-125.

Handcock, M. S., Hunter, D. R., Butts, C. T., Goodreau, S. M., \& Morris, M. (2008). Statnet: Software tools for the representation, visualization, analysis and simulation of network data. Journal of Statistical Software, 24(1). http://dx.doi.org/10.18637/jss.v024.i01

Hofmann, H. C. H. (2008). Mapping the European administrative space. West European Politics, 31(4), 662-676.

Keohane, R. O., \& Nye, J. S. (1974). Transgovernmental relations and international organizations. International Organization, 27(1), 39-62.

Kettunen, P., Lundberg, U., Österberg, M., \& Petersen, K. (2016). The Nordic model and the rise and fall of Nordic cooperation. In J. Strang (Ed.), Nordic cooperation: A European Union in transition (pp. 69-92). Abingdon: Routledge.

Lawler, P. (1997). Scandinavian exceptionalism and European Union. Journal of Common Market Studies, 35(4), 565-594.

Leruth, B., Gänzle, S., \& Trondal, J. (2019). Differentiated integration and disintegration in the EU after Brexit: Risks versus opportunities. Journal of Common Market Studies, 57(6), 1383-1394.

Martinsen, D. S., Schrama, R., \& Mastenbroek, E. (2020). Who interacts with whom? Drivers of networked welfare governance in Europe. British Journal of Political Science. Advance online publication. https://doi.org/ 10.1017/S0007123420000204

Mastenbroek, E., \& Martinsen, D. S. (2018). Filling the gap in the European administrative space: The role of administrative networks in EU implementation and enforcement. Journal of European Public Policy, 25(3), 422-435.

Murata, T. (2010). Detecting communities in social networks. In B. Furht (Ed.), Handbook of social network technologies and applications (pp. 269-280). Boston, MA: Springer.

Ojanen, H. (1999). The plurality of truth: A critique of research on the State and European integration. Abingdon: Routledge.

Olesen, T. B., \& Strang, J. (2016). European challenge to Nordic institutional cooperation: Past, present and future. In J. Strang (Ed.), Nordic cooperation: A European region in transition (pp. 27-47). Abingdon: Routledge.

Olsen, J. (2003). Towards a European administrative space? Journal of European Public Policy, 10(4), 506-531.

Pons, P., \& Latapy, M. (2005). Computing communities in large networks using random walks. Paper presented at the 20th International Symposium on Computer and Information Sciences, Istanbul, Turkey.

Rose, R. (1993). Lesson-drawing in public policy: $A$ guide to learning across time and space. Chatham: Chatham House.

Sabel, C. F., \& Zeitlin, J. (2008). Learning from difference: The new architecture of experimentalist governance in the EU. European Law Journal, 14(3), 271-327.

Schimmelfennig, F., Leuffen, D., \& Rittberger, B. (2015). The European Union as a system of differentiated integration: Interdependence, politicization and differentiation. Journal of European Public Policy, 22(6), 764-782.

Slaughter, A. (2004). A new world order. Princeton, NJ: Princeton University Press.

Slaughter, A., \& Hale, T. (2010). Transgovernmental networks. In M. Bevir (Ed.), The Sage handbook of governance (pp. 342-351). London: Sage.

Snijders, T. A., Pattison, P. E., Robins, G. L., \& Handcock, M. S. (2006). New specifications for exponential random graph models. Sociological Methodology, 36(1), 99-153.

Strang, J. (2016). The Nordic model of transnational cooperation? In J. Strang (Ed.), Nordic cooperation: $A$ European Union in transition (pp. 1-26). Abingdon: Routledge.

Sundelius, B. (1977). Trans-governmental interactions in the Nordic region. Cooperation and Conflict, 12(2), 63-85.

Sundelius, B., \& Wiklund, C. (1979). The Nordic Community: The ugly duckling of regional cooperation. Journal of Common Market Studies, 18(1), 59-76.

Sundelius, B., \& Wiklund, C. (2000). Norden i sicksack: tre spårbyten inom nordiskt samarbete [The zigzagging North: Three changes of track in Nordic cooperation]. Stockholm: Santérus förlag.

Sverdrup, B. O. (1998). Europeisering som deinstitusjonalisering-nordisk politisk smarbeid i endring [Europeanisation as de-institutionalisationNordic political cooperation in change]. In $\mathrm{T}$. Aschehoug (Ed.), Europa i Norden. Europeisering av nordisk samarbeid [Europe in the North: Europeanisation of Nordic cooperation] (pp. 162-194). Oslo: Tano Aschehoug.

Tervonen, M. (2016). The Nordic passport union and its discontents: Unintended consequences of free movement. In J. Strang (Ed.), Nordic cooperation: A European region in transition (pp. 131-145). Abingdon: Routledge.

Trondal, J. (2010). An emergent European executive order. Oxford: Oxford University Press.

Trondal, J., \& Peters, B. G. (2013). The rise of European administrative space: Lessons learned. Journal of European Public Policy, 20(2), 295-307.

Van Der Heijden, M. (2019). Agencies without borders: Explaining partner selection in the formation of transnational agreements between regulators. Regulation \& Governance. Advance online publication. https://doi.org/10.1111/rego.12295

Vantaggiato, F. P. (2019). The drivers of regulatory networking: Policy learning between homophily and convergence. Journal of Public Policy, 39(3), 443-464.

Vantaggiato, F. P., Kassim, H., \& Wright, K. (2020). Internal network structures as opportunity structures: Control and effectiveness in the European 
competition network. Journal of European Public Policy. Advance online publication. https://doi.org/ 10.1080/13501763.2020.1737183

Versluis, E., \& Tarr, E. (2013). Improving compliance with European Union law via agencies: The case of the European Railway Agency. Journal of Common Mar- ket Studies, 51(2), 316-333.

Wendt, C. (2009). Mapping European healthcare systems: A comparative analysis of financing, service provision and access to healthcare. Journal of European Social Policy, 19(5), 432-445.

\section{About the Authors}

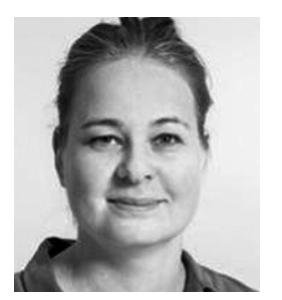

Reini Schrama is Postdoctoral Researcher at the University of Copenhagen, Department of Political Science. Her expertise is in the implementation and enforcement of EU policy and networked governance in the social and health policy domain.

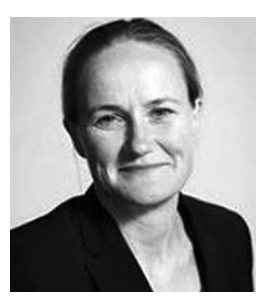

Dorte Sindbjerg Martinsen is Professor at the University of Copenhagen, Department of Political Science. Her research focuses on EU welfare policies, investigating integration, national implementation of and compliance with EU social policies, including health care.

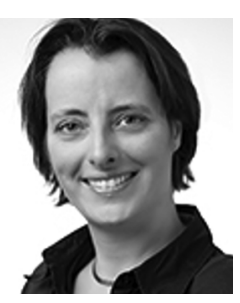

Ellen Mastenbroek is Professor of European Public Policy at Radboud University. Her main research interests are the Europeanisation of national governments and EU policy analysis, focusing on compliance, implementation and evaluation of EU legislation. 